\title{
Redes en la génesis y desarrollo de un distrito papelero catalán: el caso de Capellades (siglo XIX)
}

\author{
Networks in the origin and development of a Catalan papermaking district: \\ the case of Capellades (19th century)
}

\author{
MIQUEL GUTIÉRREZ I POCH \\ Universidad de Barcelona
}

RESUMEN

La comarca de Capellades (Barcelona), junto a la de Alcoy, lideró la expansión de la manufactura papelera española del siglo XVIII. Esta comarca no adoptó la fabricación continua durante el proceso de mecanización de la centuria posterior y continuó elaborando el papel manualmente. Ésta no fue una decisión guiada por el atavismo. Esta opción tecnológica fue una respuesta a su especialización productiva (papel de calidad y de fumar), la cual continuaba teniendo demanda. El modelo tecnológico reseñado, que además no fue estático, fue exitoso como fruto de las dinámicas de distrito y la articulación de una densa red de suministro de materias primas y de comercialización. Sin estos elementos es muy difícil entender cómo

unas empresas muy pequeñas han podido sobrevivir hasta el presente y ocupar, en ocasiones, posiciones de liderazgo en determinados mercados.

PALABRAS CLAVE: Redes, Distritos industriales, Industria papelera, Cataluña, España

Códigos JEL: L22, L23, N63, N93

\section{ABSTRACT}

The area of Capellades (Barcelona), together with the Alcoy one, led the Spanish papermaking manufacture growth during the eighteenth century. Later on, during the mechanization process of the nineteenth century, this area did not adopt the continuous fabrication technique and went on making paper by hand. This decision was not guided by atavism. Such a technological option was an answer to its productive specialization (quality paper and cigarette paper) which could still benefit from a substantial demand. This technological model, which was not static, was successful thanks to the district dynamics and the establishment of a dense network for raw materials supply and for paper commercialisation. Without taking into account all these factors, it is very difficult to understand why very small firms have survived until the present and have been even able to hold leading positions in some paper markets.

KEY WORDS: Networks, Industrial Districts, Papermaking Industry, Catalonia, Spain

JEL Codes: L22, L23, N63, N93 


\section{Introducción ${ }^{1}$}

$\mathrm{E}$ l contrato es el fiel de una balanza en cuyos respectivos brazos, en la visión de la economía de los costes de transacción, se sitúan el mercado y la empresa. Este planteamiento obvia la naturaleza histórica de la empresa. Además, puesto que la empresa es utilizada cuando el fiel indica que los costes de transacción son menores que en el mercado, aquélla resulta ser siempre la gran empresa y no sorprende que se apele a los autores que han señalado su centralidad. Sin embargo, estos historiadores económicos y de la empresa (Alfred D. Chandler ${ }^{2}$ y William Lazonick $^{3}$, de modo destacado) han ignorado o minusvalorado otras fórmulas de organización. Últimamente se han señalado los límites del enfoque "chandleriano"4 y se han admitido formas híbridas de empresa y de mercado 5 . Esto ha permitido recuperar protagonismo a las pequeñas y medianas empresas y a la producción flexible, reforzando la diversidad de la estructura industrial incluso en los tiempos de las grandes corporaciones ${ }^{6}$.

Dos conceptos presentes en las formulaciones alternativas al enfoque "chandleriano" son el de distrito industrial y el de red". La idea de distrito parte de Alfred Marshall, quien explicaba la concentración geográfica de una actividad en función de tres variables: la existencia de un mercado de mano de obra especializada compartido por la totalidad de las empresas, la disponibilidad de actividades complementarias que facilitan el aprovisionamiento de materias primas y productos intermedios y, por último, una mejor y mayor difusión de los cambios técnicos. En ese marco, donde actúan las economías externas y los rendimientos crecientes, las pequeñas y medianas empresas reducen sus costes y aumentan su competitividad. En la reactivación teórica reseñada han coincidido la nueva teoría del comercio inter-

[Fecha de recepción del original, junio de 2007. Versión definitiva, octubre de 2007]

1 Este artículo forma parte del proyecto de investigación SEJ 2005-02498, dirigido por Jordi Catalan. Una versión previa fue presentada al X Simposio de Historia Económica (Bellaterra, septiembre 2005). Agradezco los comentarios de Jesús M. Valdaliso, de Josep M. Benaul y de los cuatro evaluadores anónimos de Investigaciones de Historia Económica.

2 Chandler (1987) y (1996).

3 Lazonick (1991). Sin embargo, Lazonick destaca cómo la innovación en la empresa depende del entorno institucional y de los períodos (Lazonick, 2004).

4 Richard N. Langlois ha afirmado que "la empresa 'chandleriana' ya no domina todo el paisaje" (Langlois, 2004, p. 355). Según Steven Toms y John F. Wilson, "el enfoque 'chandleriano' ofrece un acercamiento que sólo se adecua parcialmente a la historia de la empresa internacional” (Toms y Wilson, 2003, p. 1).

5 Entre las reformulaciones de Chandler, véanse Langlois (2003) y Lamoreaux, Raff y Temin (2003). Langlois formula la hipótesis de "the vanishing hand", según la cual el mercado ha cobrado protagonismo en el seno de la nueva economía. Lamoreaux, Raff y Temin intentan superar la dicotomía entre mercados y jerarquías para situar a las relaciones duraderas como una alternativa.

6 Véanse, entre otros, Scranton (1991) y (1997), Berger y Piore (1980), Sabel y Zeitlin (1985), y Piore y Sabel (1990).

7 No debe ignorarse que gran empresa no es siempre un concepto excluyente de los de distrito industrial y red. 
nacional, la New Economic Geography ${ }^{8}$, trabajos sobre el empuje innovador de los clusters $^{9}$ y los milieux innovateurs, y la literatura "becattininiana"10. Con frecuencia estos conceptos, y algunos otros, se han utilizado de forma errónea como sinónimos ${ }^{11}$. Paul Krugman ha contribuido a reactivar el potencial teórico del concepto de distrito apostillando que la concentración de cualquier actividad económica se origina en la interacción entre los rendimientos crecientes, los costes de transporte y la deman$\mathrm{da}^{12}$. Un concepto complementario, que no sinónimo, de distrito es el de red, ya que las industrias concentradas territorialmente potencian su articulación ${ }^{13}$ y la coordinación formal o informal ${ }^{14}$. El objetivo de estas acciones es reducir los costes de transacción, especialmente los de información, responder a la incertidumbre ${ }^{15}$ y aumentar la competitividad ${ }^{16}$. La pieza central en la aparición y desarrollo de las redes, partiendo de un sistema común de valores, es la confianza mutua entre sus miembros y la existencia de una cultura de cooperación ${ }^{17}$.

La historia económica y la historia empresarial han participado del resurgimiento de la localización y del distrito industrial ${ }^{18}$ y de las redes ${ }^{19}$. Este enfoque tam-

Los trabajos de Krugman han sido la base principal de la nueva teoría del comercio internacional y de la New Economic Geography. Para una síntesis de los modelos básicos de esta última, véanse Ottaviano y Puga (1998), Robert-Nicoua (2005), y Ottaviano y Robert-Nicoua (2006).

9 Porter señala cómo los clusters contribuyen a aumentar la productividad, a mejorar la capacidad de innovación y a estimular la creación de nuevas empresas (Porter, 1990). Para un repaso de la literatura sobre la innovación técnica y la transmisión del conocimiento en los clusters, véase Breschi y Malerba (2001). Giacomo Becattini y sus discípulos (Bellandi, Sforzi, Guenzi, Dei Ottati, Lazaretti, entre otros) han destacado el protagonismo de la pequeña y mediana empresa en estructuras concentradas territorialmente. La "escuela de Florencia" pone al distrito en primer plano y no al sector o a la empresa. El impacto de los trabajos de Becattini en España tuvo su primer referente en la traducción al catalán en 1986 del artículo "Dal settore industriale al distretto industriale..." (Becattini, 1986), cuyo original italiano databa de 1979. La vigencia de este enfoque en España viene avalada por el número de Economía Industrial publicado en 2006 con el título "El distrito industrial 'marshalliano'. Un balance crítico de 25 años", y la traducción al castellano de Il Bruco e la farfalla... (Becattini, 2005). Reflejo de este vigor son los trabajos de Joan Trullén, Maria Teresa Costas, Vicent Soler, Josep-Antoni Ybarra y Rafael Boix, entre otros.

11 Para una aproximación "becattiniana" a las diferencias entre el cluster de Porter y el distrito industrial, véase Lazzeretti (2006). Becattini califica al cluster de Porter como un "compañero de viaje [...] cuya compañía se ha vuelto [...] embarazosa" (Becattini, 2006, p. 23).

12 Krugman (1992), p. 20. Roos ha destacado cómo estos factores, los llamados second nature, son más trascendentes, incluso, que la dotación de factores naturales (Roos, 2005).

13 Wilson y Popp (2003b), p. 355.

14 Enright (1995).

15 Corolleur y Courlet (2003).

16 Lechner y Dowling (2003).

17 Casson (1997), Casson y Della Giusta (2004).

18 Nick Crafts y Abay Mulatu han analizado cómo en la localización industrial en Gran Bretaña entre 1871 y 1931 pesó más la dotación de factores que las variables contempladas por la New Economic Geography (Crafts y Mulatu, 2005). Los mismos autores muestran cómo la reducción de los costes de transporte tuvo un reducido impacto en la localización de la industria (Crafts y Mulatu, 2006). Para un estado de la cuestión de la literatura sobre distritos a escala británica, véase Wilson y Popp (2003a).

19 Obras de referencia desde el ámbito de la business history son Brown y Rose (1993) y Rose (2000). 
bién ha proliferado en España, donde se ha demostrado cómo el sector lanero ${ }^{20}$ y el del zapato ${ }^{21}$, entre otros, han basado su configuración en sendos distritos industriales. Las visiones globales de la localización y el papel jugado por la dinámica de distrito han partido del trabajo pionero de Nadal, que constataba la concentración fabril en Cataluña ${ }^{22}$. En los posteriores avances, las externalidades "marshallianas" han constituido una variable recurrente, partiendo de escalas regionales, provinciales o locales. La controversia se ha centrado en buscar la causalidad de la concentración en los factores naturales o en la proximidad de la demanda ${ }^{23}$.

La generalización de ambos conceptos ha llevado a interpretaciones sesgadas e, incluso, abusivas ${ }^{24}$. Respecto al distrito, en primer lugar se ha enfatizado la concentración productiva monosectorial (o con pocos sectores). Ello omite realidades productivas multisectoriales, cuestión que mueve a recuperar la importancia de las relaciones interindustriales. En segundo lugar, es habitual caracterizar los distritos como articulados por pequeñas y medianas empresas dedicadas a una fase del proceso productivo. La consecuencia es una imagen igualitaria que no siempre se ajusta a la realidad, ya que a menudo existen una jerarquía o empresas que realizan todo el ciclo productivo. Tercero, la existencia de una cultura de la confianza no debe ocultar que las empresas buscan su propio beneficio ${ }^{25}$. Dicho de otra forma, el distrito

20 Antonio Parejo concluye que la concentración de la industria lanera en Cataluña durante la segunda mitad del siglo XIX supuso su declive en otras regiones. Sin embargo, alguna de estas últimas pudo dar el salto hacia la mecanización, determinando, de este modo, la desaparición de la manufactura tradicional de su entorno geográfico. Asimismo, Parejo señala cómo, en un contexto de diferenciación regional, se produjo la persistencia de formas tradicionales de producción (Parejo, 1987, pp. 40-44; y Parejo, 1989, pp. 19-32). Josep M. Benaul ha analizado la dinámica de distrito en los centros laneros de Terrassa y Sabadell, cuyo predominio a escala española fue claro (Benaul, 1996).

21 José Antonio Miranda ha afirmado que la primacía balear y valenciana en la industria zapatera tenía su origen en las economías externas que "fueron fundamentales para contrarrestar la ventaja inicial de la industria catalana" (Miranda, 1999, p. 1.338). En su análisis comparativo de los distritos industriales españoles e italianos advierte cómo, en ambos casos, el dinamismo exportador se derivó de una ventaja competitiva sustentada en la dinámica de distrito (Miranda, 2005).

22 Nadal (1987).

23 Los trabajos de Rosés y los de Tirado, Paluzie y Pons polarizan el debate. Rosés, contraponiendo el modelo de Herckscher-Ohlin y los rendimientos crecientes, concluye que el fracaso o el triunfo de la industrialización de las regiones españolas responde a una combinación de ambos factores (Rosés, 2003). Tirado, Paluzie y Pons destacan el papel de la articulación del mercado interior como el elemento clave en la concentración de la actividad industrial en ciertas regiones, reforzando las economías de escala y externas preexistentes (Tirado, Paluzie y Pons, 2002). Concha Betrán, tomando una base provincial, estudia el proceso de diversificación industrial durante el primer tercio del siglo XX. Sus conclusiones son que el proceso afectó a la mayoría de las provincias (Betrán, 1999). Antonio Parejo ha incorporado la "ciudad industrial" en el análisis de largo plazo para concluir que "para la Nueva Geografía Económica la ciudad es el laboratorio en el que se materializan las externalidades dinámicas y para las teorías de los distritos industriales el territorio en el que confluyen sistema productivo y sistema social" (Parejo, 2006, p. 77).

24 Para una visión crítica de la universalización del concepto de distrito "becattiniano", véase Daumas (2007).

25 Véase Dei Ottati (1996). 
sería una forma localizada de competencia donde existe un conjunto de normas que regulan a los agentes. Así las cosas, la dinámica cooperativa desaparece cuando los inconvenientes superan a las ventajas. Es decir, que sería erróneo analizar apriorísticamente el distrito (y la red) sin observar, y entender, la dinámica individual de sus empresas. Los distritos (y las redes) son elementos dinámicos y en continúa tensión. Entre sus ventajas destaca la versatilidad. Por tanto, existe gran variedad de distritos (y redes) en función del grado de coordinación, de formalización, de la existencia de jerarquías, etc.

Este trabajo intenta contribuir, a través de un enfoque de caso y del análisis de la dinámica de distrito, al debate suscitado en la historiografía en torno a la localización industrial. El ámbito de estudio es la "comarca" papelera de Capellades durante los siglos XVIII y, especialmente, XIX ${ }^{26}$. Este distrito papelero, enclavado en la Cataluña central y cercano a Igualada, formaba parte de una zona con antigua tradición manufacturera (en el sector textil y en los curtidos) y con una viticultura de importancia ${ }^{27}$. El objetivo es apreciar como pequeñas empresas familiares de fabricación de papel vivieron el proceso de mecanización. Su apuesta estratégica fue el mantenimiento de la tecnología tradicional, respondiendo a la particular estructura del mercado español (escaso peso del papel de impresión y una significativa presencia del papel de Estado y del de fumar). Esta opción estaba, sin embargo, lejos del atavismo organizativo y productivo. De hecho, las empresas contaban con una fuerte vocación innovadora plasmada en la creación de nuevos productos. El mejor refrendo de este espíritu era su proyección exportadora. La pervivencia, e incluso dinamismo, de la fabricación manual distinguió internacionalmente la estructura del sector papelero español ${ }^{28}$. Para enmarcar adecuadamente la pervivencia del papel manual es necesaria la comprensión de la lógica productiva y comercial de dicha manufactura. La fabricación manual imponía un tamaño de planta reducido y con escasas posibilidades de introducir economías de escala. El aumento de la producción pasaba, hasta la incorporación de las máquinas picardo ${ }^{29}$, por la multiplicación de unidades productivas: las tinas. La supremacía del distrito catalán encuentra una de sus explicaciones en las economías de aglomeración que favorecieron la articulación de unas redes que, a su vez, posibilitaron un aprovisionamiento más eficiente de materias primas y una óptima comercialización. Estas

26 Véase Gutiérrez (1999). Capellades era el centro del distrito que alcanzaba a la Pobla de Claramunt, la Torre de Claramunt, Carme, Orpí, Vilanova del Camí, Òdena, Cabrera, Montbui y algún otro pueblo cercano.

27 Sobre la agricultura de la comarca del Anoia, véase Valls (1996); una visión de su industria en Torras (1974); y un estudio acerca de su sistema de intercambios durante el siglo XIX en Pascual (1990).

28 Gutiérrez (1994).

29 La picardo es una máquina que mecanizaba la fabricación del papel hoja a hoja. Este ingenio elaboraba el equivalente a 4 ó 5 tinas de un papel muy similar al manual. 
estructuras organizativas se cimentaron con la expansión de la manufactura durante la segunda mitad del siglo XVIII y alcanzaron su pleno desarrollo durante las décadas centrales del XIX. El artículo está dividido en dos apartados. El primero, centrado en el siglo XVIII, es introductorio. El segundo, el central del trabajo, se dedica al siglo XIX.

\section{Los orígenes de la concentración papelera del Anoia: el siglo XVIII}

El mercado español de papel durante el siglo XVII y buena parte del XVIII fue cubierto en gran medida por franceses y genoveses. Dos factores permitieron romper con esta situación: una política explícita de sustitución de importaciones y la expansión de la demanda originada por la Corona (los Reales Asientos para el Real Sello y para el estanco mexicano del tabaco). En esa coyuntura, los molinos aumentaron de unos 200 en la década de 1760 a unos 400 a finales del siglo. En paralelo, la manufactura se concentró en Cataluña y el País Valenciano, que pasaron de poseer alrededor del 40 por 100 de los molinos en la década de 1760 a superar el 70 por 100 en la de 1790. También en el seno de ambas regiones el sector se fue concentrando. En Cataluña lo hizo en cuatro comarcas fluviales: Anoia, Francolí-Brugent, Riudebitlles y Fluvià-Terri. Las cuatro tenían acervo papelero, como mínimo, desde el siglo XVII y reunían en el último cuarto del siglo XVIII entre el 70 y el 75 por 100 de los molinos catalanes. La concentración fue incluso mayor en el caso valenciano, alrededor de Alcoy y, secundariamente, de Onteniente y Buñol. El crecimiento de la manufactura papelera alcoyana fue súbito, ya que su primer molino databa de 1755 y a finales de siglo superaba los treinta ${ }^{30}$. El desarrollo alcoyano fue deudor casi en exclusiva del papel de fumar, mientras que la gama producida en Capellades era más amplia. Al margen de ambas regiones mediterráneas, sólo destacaban algunos núcleos en Málaga o en Teruel. En el resto de España no existía ninguna concentración papelera significativa, o cuando había existido ya había periclitado ${ }^{31}$. Por tanto, se podría apuntar la hipótesis de que la eclosión del papel catalán y valenciano fue paralela al declive del papel de la España interior.

La comarca papelera regada por el Anoia y sus afluentes, y con capitalidad en Capellades, es el mejor paradigma del desarrollo catalán. La fabricación de papel ocupó una posición secundaria, pero creciente, hasta mediados del siglo XVIII. De

\footnotetext{
30 Véanse Aracil y García Bonafé (1974), y Cuevas (1999).

31 Según la estimación propia, utilizada en el Cuadro 1, en la España interior (ambas Castillas y Madrid) en la década final del siglo XVIII funcionaban unos treinta molinos.
} 


\section{CUADRO 1}

MOLINOS PAPELEROS DE LA COMARCA DE CAPELLADES, CATALUÑA Y ESPAÑA, 1728, 1766, 1775 y 1800

\begin{tabular}{|c|c|c|c|c|c|c|}
\hline & 1728 & 1766 & & 1775 & & 1800 \\
\hline & $\begin{array}{l}\text { Número de } \\
\text { molinos }\end{array}$ & $\begin{array}{l}\text { Número de } \\
\text { molinos }\end{array}$ & $\begin{array}{l}\text { Número de } \\
\text { molinos } \\
\text { (A) }\end{array}$ & $\begin{array}{l}\text { Capacidad de } \\
\text { producción, } \\
\text { en resmas } \\
\text { (B) }\end{array}$ & $B / A$ & $\begin{array}{l}\text { Número de } \\
\text { molinos }\end{array}$ \\
\hline Anoia & 14 & 19 & 29 & 91.400 & 3.152 & 46 \\
\hline Cataluña & 35 & 69 & 109 & 305.400 & 2.802 & 200 \\
\hline España* & 78 & 200 & & & & 400 \\
\hline
\end{tabular}

$\left(^{*}\right)$ La estimación propia procede de ubicar localmente los molinos e incluir sólo aquéllos sobre los que se tiene seguridad de que funcionaban en las décadas de 1720, 1760 y 1790, respectivamente. Ello, junto a datos de diferente tipo (catálogos de patrimonio y listados) que no permiten datar exactamente la puesta en marcha de los molinos, lleva a suponer que la estimación es defectiva, especialmente para las décadas de 1760 y 1790. La corrección aplicada ha elevado el número de los 128 estimados para 1766 a 200; y en 1800 de 338 a 400.

Fuentes: Para 1728, datos corregidos de Madurell (1972, p. 1.104) para Anoia y Cataluña, estimación propia para España. Para 1766, Madurell (1972, pp. 1.130-1.132) para Anoia y Cataluña, La Lande (1778, p. 149) para España (una estimación propia sitúa el número de molinos en 128). Para 1775, Madurell (1972), pp. 61-64. Para 1800, Gutiérrez (1999, p. 109) para Anoia; Laborde (1809, vol. IV, p. 330) para Cataluña (en 1792); estimación propia para España.

diecinueve molinos en 1766 se pasó a veintinueve en 1775, y a entre cuarenta y cinco y cincuenta a principios del siglo XIX (cuyo peso relativo sobre la capacidad catalana se situaba entre el 25 y el 30 por 100, como recoge el Cuadro 1). En 1800 era, junto a Alcoy, la mayor concentración papelera catalana y española. En este marco entraron en juego las dinámicas de distrito industrial que, a su vez, alimentaron el crecimiento. Con frecuencia, esas fuerzas excedían los límites de la propia comarca, fruto de su cooperación con el núcleo de La Riba y con el de Sant Pere de Riudebitlles.

La familia, y la complicidad fruto del mismo origen geográfico, eran la base del sistema productivo. Los Romaní, una estirpe llegada desde tierras gerundenses a Capellades en la década de 1620, fueron pioneros en la creación de molinos papeleros. Su acción, completada por otros linajes, puso a la zona en el mapa papelero español. En el propio molino la mano de obra estaba compuesta básicamente por familias, ya que gran parte de las mujeres y niños que realizaban trabajos sin cualificar eran, respectivamente, esposas e hijos de los operarios especializados. La raíz familiar del trabajo viene avalada por la fuerte transmisión intergeneracional de los cono- 
cimientos $^{32}$ y la elevada endogamia ${ }^{33}$. Los papeleros de la comarca de Capellades, una vez agotadas las posibilidades de expansión en su zona, se establecieron en otras. Esta estrategia venía refrendada por el control de los Asientos, por el óptimo aprovisionamiento de las materias primas y por la disponibilidad de excedentes de mano de obra cualificada. De hecho, a partir de 1730, la comarca del Anoia nutrió de operarios cualificados a otras zonas papeleras catalanas y españolas. Muchos de los desplazados mantenían un contacto perenne con su zona de origen a través de las relaciones familiares y del uso de sus servicios técnicos.

La estructura organizativa de la producción no era igualitaria. La cúspide de la jerarquía la ocupaba media docena de familias (los Romaní, los Guarro, los Ferrer, los Farreras, entre otros) con frecuentes matrimonios cruzados entre ellos e, inclusive, con familias dominantes de otras comarcas. Un elemento jerarquizador de partida era contar, o no, con la propiedad del molino. Este selecto grupo de familias poseía la mayoría de instalaciones. Ello no quiere decir que los molinos propiedad de miembros de la misma familia funcionaran como una sola "empresa". De hecho cada uno gozaba de plena autonomía, aunque podían coordinarse ocasionalmente. Un segundo elemento definitorio del grupo dominante fue el control de los Reales Asientos, ya que eran firmados por un núcleo reducido de papeleros. El resto de fabricantes suscribía pactos con éstos para librarles una determinada cantidad de papel en el seno de la contrata. La oligarquía controlaba a los subcontratistas en lo relativo al cumplimiento de los plazos y a las características del producto. Las prácticas oportunistas podían acarrear la expulsión de la contrata y comprometer el futuro de su autor en el sector. El reducido grupo oligárquico reforzó su control de la manufactura a través de su presencia en cargos municipales y en aquéllos relacionados con la propia manufactura ${ }^{34}$. La jerarquía no fue estática ni indiscutida. Algunas familias salían de las posiciones hegemónicas, bien al adoptar un comportamiento rentista, bien por dificultades en sus negocios, mientras que otras las ocupaban después de su enriquecimiento. La dinámica de subcontratación se extendía a otras zonas papeleras como la Riba o Sant Pere de Riudebitlles. Los fabricantes de ambas comarcas pretendieron poner en entredicho el papel de los de Capellades, al tratar de obtener directamente el Asiento, pero el intento fue infructuoso ${ }^{35}$.

32 En la Pobla de Claramunt únicamente 11 de los 67 hijos de papeleros casados entre 1685 y 1813 no se dedicaban a esta actividad. Archivo Parroquial de la Pobla de Claramunt (APPC, en adelante), Registros de Matrimonios, 1685-1813.

En la Pobla de Claramunt, entre 1766 y 1804, el 43,3 por 100 de los maridos de hijas de papeleros tenían la misma profesión.

34 Esta posición de preeminencia fue explicitada por la Junta de Comercio de Barcelona en 1776, cuando se nombró para ocupar el cargo de veedores del sector a Francesc Guarro y Antoni Romaní, ambos destacados papeleros de la zona de Capellades. Madurell (1972), p. 134.

35 Archivo General de Simancas (AGS, en adelante), Secretaría y Superintendencia de Hacienda, leg. 2.337. 
La atmósfera cooperativa existente entre los papeleros de la zona es incontestable, como también lo es que los pactos eran meramente funcionales y estratégicos. La coexistencia de fuerzas favorecedoras de la cooperación con otras favorables a la competencia viene avalada por tres aspectos: el suministro de agua, el aprovisionamiento de materias primas y la comercialización (y la articulación de un lobby en Madrid).

Respecto del agua, usada como fuente energética y en el propio proceso de fabricación, los papeleros hicieron causa común en las luchas con los señores jurisdiccionales, como sucedió en Capellades con el cenobio benedictino de Sant Cugat del Vallès ${ }^{36}$, y frente a otros usuarios de esas aguas (hortelanos, fabricantes de aguardiente y paraires) ${ }^{37}$. La cooperación no impidió enfrentamientos entre papeleros por su mal uso o cuando se pretendía aumentar su consumo.

La materia prima esencial era el trapo de fibra vegetal (lino, algodón, cáñamo) ${ }^{38}$, cuya oferta era restringida, inelástica a corto plazo y dispersa en el espacio. Estas características imponían una captación con elevados costes de transacción y una compleja logística. Otro input fundamental eran las carnazas, restos animales de alto contenido gelatinoso, utilizadas en el encolado del papel y cuya oferta se concentraba en los centros de curtido de pieles. En ambos casos, eran bienes voluminosos y de bajo precio relativo, lo que exigía que sus tráficos se insertasen en otros flujos comerciales para moderar sus costes. La comarca de Capellades gozaba de una situación privilegiada para su suministro. En primera instancia la cruzaba un corredor natural entre el litoral catalán y el interior español recorrido por el Camino Real de Barcelona a Madrid. Asimismo contaba con una oferta importante y estable de transporte ${ }^{39}$ y con una estructura económica diversificada, orientada hacia el mercado e integrada. A ello debe sumarse la cercanía de Barcelona, donde, como en todas las ciudades, se concentraba una importante oferta de trapo, cuyo flujo de entrada se veía facilitado, además, por la intensa actividad de su puerto ${ }^{40}$. En el caso de las carnazas debe

El monasterio esgrimía antiguos derechos y el consistorio el derecho comunal a usar el agua. Ello motivó un largo pleito con intervención real. Archivo de la Corona de Aragón (ACA, en adelante), Real Patrimonio, Batllia, Procesos Modernos, Proceso de 1777, n 7: "El ayuntamiento de Capellades sobre precario". Un ámbito de conflicto se estableció con los hortelanos, aunque el antagonismo más clarificador fue el mantenido con los laneros (fruto de la suciedad que su actividad producía en el agua).

En la fabricación de diez resmas eran necesarios entre 62 y 70 kilogramos de trapo.

39 El dinamismo económico del Anoia explica que en una memoria de 1779 se hablara de la existencia en Igualada de treinta y dos carros "en incesante ejercicio" (Torras, 1993, p. 277). A dichos transportistas se sumaban campesinos que se dedicaban a esta actividad estacionalmente. Incluso, poblaciones próximas, como Calaf y Copons, se especializaron en esta actividad (Muset, 1997). Ocasionalmente también utilizaban la oferta de transporte procedente de Barcelona. En otras zonas papeleras de España el transporte se debía internalizar en el propio molino con el lógico sobrecoste que ello conllevaba. Esto era habitual en molinos de la España interior, como los de Palomera (Cuenca), que en 1727 disponían de seis recueros (Larruga, 1787-1800, XIX, pp. 197-199).

40 En 1790 se decía que el trapo usado en Capellades procedía de “Cádiz, Castilla, Aragón, Valencia y demás partes". Torras (1993), p. 492. 
destacarse que Igualada era un importante núcleo curtidor. Los factores reseñados se veían reforzados por los de índole jurídica, como el derecho de tanteo derivado de los Reales Asientos. Todo ello, junto a la propia concentración productiva, facilitó un aprovisionamiento de materias primas más eficiente. Los papeleros del distrito de Capellades pronto lograron abastecerse directamente de trapo y romper, por ende, su inicial dependencia con respecto a los comerciantes barceloneses en la provisión de dicha materia prima. La ventaja frente a los competidores se demostró durante la subida de precios del trapo en la década de 1770, causada por los crecientes pedidos de papel de fumar para Nueva España. La respuesta fue doble: la compra mancomunada en Cataluña (un acuerdo firmado en 1773 fue asumido, más tarde, por papeleros de Sant Pere de Riudebitlles y la Riba y persistió hasta 1776 ${ }^{41}$ y la activación de la adquisición directa en el resto de España (a finales de la década de 1770 su red de proveedores ya estaba muy asentada ${ }^{42}$. La compra se hizo preferentemente utilizando recursos ajenos, siendo ocasional la presencia directa de los papeleros en esa red. Estas estrategias posibilitaron que los molinos de la comarca del Anoia mantuvieran durante los años de dificultades por falta de trapo una tasa de funcionamiento del 46 por 100 frente al 39 de la media catalana ${ }^{43}$.

La existencia de una estrategia común queda avalada, también, por la creación de un lobby para copar los Reales Asientos. Primero, la presión se hizo a través de procuradores madrileños o de los propios fabricantes desplazados a Madrid o Barcelona. Finalmente, miembros de familias papeleras se establecieron en la "Villa y Corte" ${ }^{\prime 4}$. Además, algunos papeleros crearon establecimientos comerciales en Madrid, si bien se trató de iniciativas aisladas más que de una auténtica red de comercialización. Ello no obsta para que los papeleros utilizaran redes ajenas, como la que operaba en la compra de cereales y de materias primas y en la comercialización de tejidos. Es de destacar que Copons, población originaria de multitud de comerciantes establecidos por toda España, estuviera cerca del distrito de Capellades y contara con un molino papelero ${ }^{45}$.

41 Archivo Histórico Comarcal de Igualada (AHCI, en adelante), Archivo Notarial de Igualada (ANI, en adelante), Igualada (456), V. Aulet, 1773 (II), f. 127-134 y f. 185-189.

42 Los fabricantes de la compañía para abastecer la fábrica de tabacos de Nueva España facultaron en 1774 a un comerciante para comprar trapo en "los Ports maritims de [...] Cádiz, Sevilla, Málaga, Cartagena y altres". AHCI, ANI, Igualada (457), V. Aulet, 1774 (I), f. 7.

$43 \quad$ Estimación basada en una encuesta datada en 1775. Madurell (1972), pp. 61-64.

$44 \quad$ El mejor ejemplo es el de Raimon Talavera Dalmases, integrante de una familia lanera de Capellades reconvertida a la fabricación de papel, que se dedicaba al comercio en Madrid, donde mantenía contactos con la plana mayor del reformismo ilustrado. Era accionista del Banco de San Carlos, miembro de su primera junta y, desde comienzos de 1785, codirector de la sucursal gaditana. Durante las décadas de 1760 y 1770 representó a los papeleros de Capellades en la negociación de las contratas de papel. 
La propia densidad papelera del distrito favoreció la aparición de una serie de servicios dedicados a la renovación y reparación del utillaje (maestros de casas, carpinteros, herreros y moldistas o formaires ${ }^{46}$ ). Con frecuencia, estos operarios procedían de familias papeleras y tenían contacto directo con la manufactura. Sus servicios eran requeridos desde otras comarcas catalanas y españolas. El distrito de Capellades, por tanto, podía responder con mayor agilidad que sus competidores a los problemas que pudieran surgir.

\section{La continuidad del papel manual en tiempos de cambio}

La introducción de la máquina continua en España fue tardía (en 1839) y modesta (había 48 en 1879). La otra cara de la moneda fue la supervivencia del papel manual fruto de la peculiar estructura de la demanda. Una vez superado el impacto causado por la irrupción del papel continuo, el de tina vivió una singular reactivación hasta 1880. En 1845, España tenía unos 280-300 molinos papeleros, lo que supondría alrededor de 400 tinas, mientras que se llegó a 531 tinas en 1856, 648 en 1863 y 757 en 1879. La hegemonía continuó correspondiendo a Cataluña y, sobre todo, al País Valenciano, que pasaron de suponer, respectivamente, el 36,2 y el 26,9 por 100 en 1856, a implicar el 32,2 y el 41,2 por 100 en 187947. Esta supremacía entrañaba la continuidad de lo acaecido en la segunda mitad del siglo XVIII. El declive de la producción a tina se gestó desde inicios de la década de 1880, funcionando únicamente 233 en 1900 y 108 en 1918. El declive catalán fue paulatino y debido a la adopción de la máquina picardo, mientras que en el País Valenciano fue súbito y atribuible al uso de la máquina continua a partir de 1885.

El distrito de Capellades continuaba ocupando un lugar central. En 1860-1865 concentraba alrededor del 9 por 100 de la capacidad española de fabricación de papel manual y cerca de una cuarta parte de la catalana. Su especialización productiva, con mayor peso relativo del papel blanco que en el resto de Cataluña - donde el de estraza tenía mayor presencia—, reforzaba su predominio habida cuenta del mayor valor añadido del primero. Su cuota productiva había aumentado en 1880 hasta el 13-15 por 100 de España y el 40-50 por 100 de Cataluña (véase el Cuadro 2). Los papeleros del Anoia habían logrado que el simple toponímico de Capellades fuera aval de calidad. En este éxito fue esencial la continuidad de una estructura

\footnotetext{
46 La forma era el tamiz utilizado para fabricar la hoja de papel con el trapo previamente triturado.

47 Fue especialmente reseñable el empuje alcoyano. En 1879 la localidad alicantina concentraba 136 tinas, que suponían el 18 por 100 del total español. Aracil y García Bonafé (1974), pp. 262-263.
} 


\section{CUADRO 2}

TINAS EN EL DISTRITO DE CAPELLADES, CATALUÑA Y ESPAÑA, 1861 Y 1879-1880

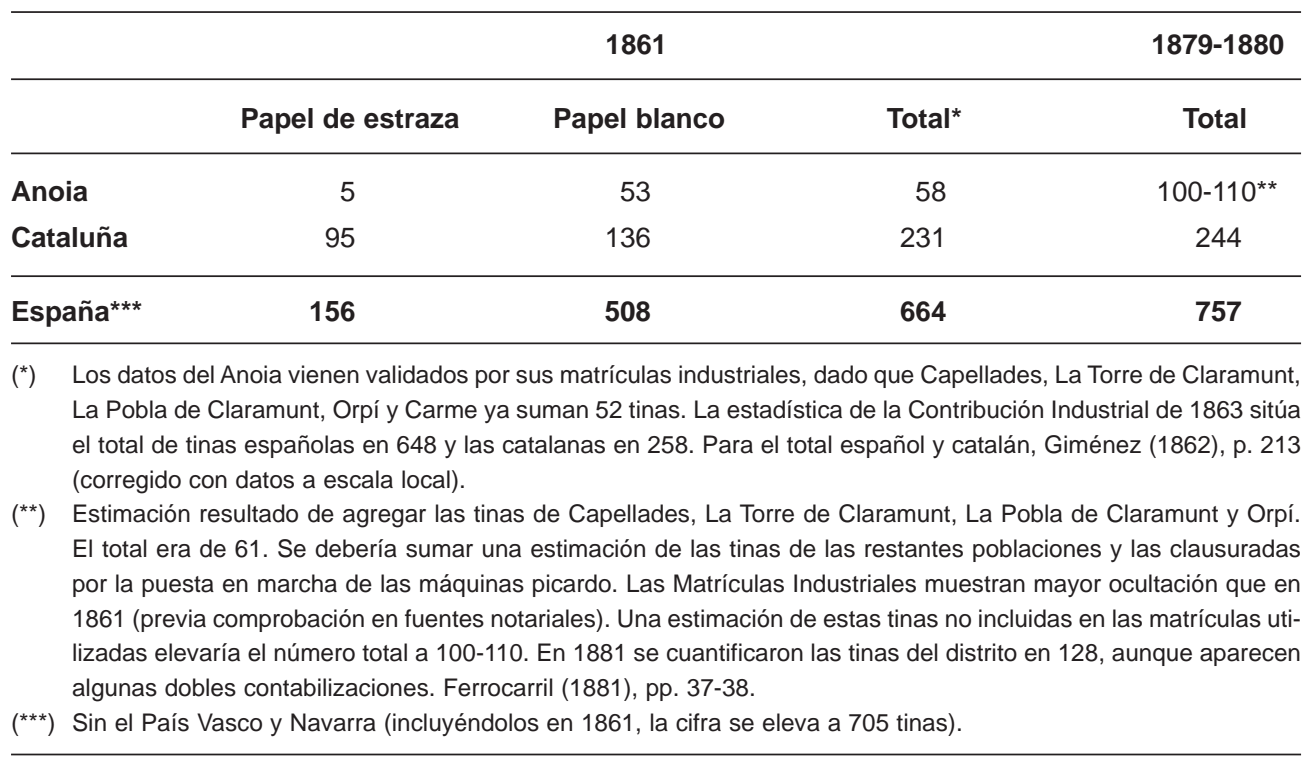

Fuentes: Las mencionadas en las notas anteriores.

empresarial vinculada a las dinámicas de cooperación y en la que la familia seguía siendo decisiva. Ejemplos de ello eran el funcionamiento descentralizado de la estructura productiva, la organización de una red comercial y de suministro, y toda una serie de estrategias cooperativas en diferentes ámbitos.

\subsection{Empresas y descentralización productiva}

La organización productiva de la manufactura estaba muy condicionada, a diferencia de otros sectores, por un proceso productivo indivisible. Con ello se impedía la existencia de pequeñas empresas de fase (con la excepción de los "pintadores", que eran unos pequeños talleres donde se aromatizaban determinados tipos de papel de fumar). La única fórmula de descentralización posible era la subcontratación de la elaboración total del producto. En ese plano debe entenderse la singularidad de su organización como distrito oligárquico.

La jerarquización del sistema productivo se agudizó durante el siglo XIX en paralelo a la continua renovación de la oligarquía. Dos de las incorporaciones más 
destacadas, las de las familias Miquel y Vilaseca, se dieron en el último tercio del siglo. Simultáneamente, otras familias adoptaron una postura rentista respecto a sus molinos y pasaron a dedicarse a profesiones liberales en Barcelona ${ }^{48}$. El colectivo hegemónico estaba formado por una media docena de papeleros que solían residir en Barcelona y se concentraban en la gestión comercial del negocio. El resto de papeleros, si eran propietarios, no controlaban las grandes contratas; los demás eran arrendatarios que seguían una vida errante por los molinos de la zona. La dependencia del segundo bloque respecto al primero se fue acentuando. De hecho, a principios del siglo XX el sector estaba dominado por tres firmas, progresivamente especializadas y líderes en sus respectivos segmentos de mercado: J. Vilaseca y Romaní T., centradas en el papel fino, y Miquel y Costas $\mathcal{E}$ Miquel, especializada en papel de fumar. Ello no obsta para la existencia de una decena de pequeñas empresas con vida más o menos autónoma.

Las funciones de la oligarquía eran coordinar la producción, ajustarla a las exigencias del mercado y desarrollar nuevos productos. Mientras, descentralizaban aquélla a través de su delegación a un encargado (en los molinos propios o en los $\operatorname{arrendados}^{49}$ ) y de la subcontratación. En el primer caso, el encargado o balaire ${ }^{50}$ gozaba de gran autonomía siempre que cumpliera con la calidad exigida y los plazos. El propietario le remitía las materias primas y el efectivo para el pago de los salarios y la manutención de los operarios. El sistema se basaba en una fuerte dosis de confianza y, con frecuencia, de parentesco ${ }^{51}$. Con todo, las supervisiones del propietario eran habituales para evitar abusos del balaire $e^{52}$, quien podía llegar a acumular capital para emprender una trayectoria empresarial propia ${ }^{53}$. La subcontratación

Ejemplo de ello fue Francesc Romaní Puigdengolas, hijo del papelero Joan Romaní Massana, que se dedicó al derecho, a las inversiones inmobiliarias y a la política.

49 El mercado de arrendamiento de molinos era cada vez más cercano al monopsonio, ya que las empresas que los demandaban eran cada vez menos y más poderosas.

50 El balaire cobraba "un interés por cada bala que se elabora, y cuida al mismo tiempo de la manutención de los mozos papeleros". La Federación, 26/09/1869, p. 3.

51 El cargo de balaire pasaba de padres a hijos. Por ejemplo, el lugar de Pau Bertrán Guilera como balaire de la familia Romaní lo ocupó, después de su muerte en 1854, su hijo Pau Bertrán Vallès. Otro molino de los Romaní, el de Martorell, fuera del distrito de Capellades, era conducido por un cuñado de Bertrán. Leandre Mateu Romaní también era balaire de su primo Antoni Romaní Tarrés. La familia lo había iniciado en la fabricación de papel trabajando con el antes mencionado Pau Bertrán. Joan Forn Tomàs, balaire de Miquel y Costas \& Miquel estaba casado con una hermana de Llorenç y Antoni Miquel Costas, fundadores de la firma.

52 Era frecuente que el balaire escamoteara, en su beneficio, cantidades dedicadas a los salarios y a la alimentación de la mano de obra.

53 Pau Bertrán Vallès, en 1862, participaba en una firma ajena a los Romaní, Vilaseca y Bertrán. Su socio era Josep Vilaseca, quien fundó una empresa que sería gran competidora de Romaní. Otro ejemplo similar, registrado medio siglo más tarde, fue el de Joan Forn, quien dejó de trabajar para Miquel y Costas \& Miquel con idéntico propósito. 
se utilizó tanto ocasionalmente (para cubrir puntas de demanda) como de forma estructural. Se basaba en que el papelero contrataba la capacidad productiva de molinos ajenos a su gestión directa, que utilizaba a su interés y que producían con su marca. En este caso la supervisión se acentuaba. El incumplimiento de lo pactado llevaba al rechazo de la partida y a la interrupción de los pedidos. En ocasiones, los gestores de estos molinos habían contado con el respaldo financiero y logístico de miembros de la oligarquía para iniciar su actividad. Con la estructura productiva reseñada, los propietarios disponían en muchas ocasiones de varios molinos situados en la misma comarca de Capellades o, incluso, en otras. Ello otorgaba al sector versatilidad y agilidad frente a la evolución y requerimientos de la demanda.

La descentralización productiva empezó a retroceder, aunque sin abandonarse del todo (especialmente la subcontratación), durante las décadas de tránsito del siglo XIX al XX, como apunta la progresiva sustitución del sistema de balaires por la administración directa. A ello contribuyeron la caída de la demanda de papel manual, la mecanización parcial que supuso la máquina picardo y las crecientes presiones sindicales.

\subsection{Las redes de compras y de comercialización: una fuente de hegemonía}

La diáspora comercial catalana del siglo XIX tiene un buen referente en los papeleros de la comarca de Capellades ${ }^{54}$. Durante el Ochocientos cuajaron fuerzas sólo apuntadas en el siglo anterior. Estas estructuras, que en forma de red alcanzaban la práctica totalidad del territorio español, tenían dos funciones: el suministro de materias primas y la comercialización del papel. A diferencia de lo sucedido en el siglo XVIII, se reforzaron tales redes estables montadas o supervisadas por papeleros o su entorno. Ello no impidió que también se emplearan recursos ajenos, como sucedía en Madrid, donde la distribución del papel de Capellades estaba en manos de los grandes mayoristas (algunos relacionados con la fabricación continua de papel) ${ }^{55}$. Los elevados costes de la estructuración y mantenimiento de una red propia se reducían

54 El sector papelero refrenda la visión tradicional de la profunda imbricación de los industriales catalanes en la comercialización. Ello contrasta con la opinión de Marc Prat y Raimon Soler, según la cual los algodoneros no estaban tan implicados en la venta de sus tejidos como se había creído, aunque su compromiso comercial aumentó en el último cuarto del siglo XIX (Prat, 2006; y Prat y Soler, 2002). Al margen de su propia red, los papeleros usaron las redes comerciales de otros sectores, como el algodonero, para sus fines.

55 Una excepción fue Pau Ferrer, ya asentado en Madrid a finales de la década de 1820. Ferrer comercializaba papel (al menos dos de sus hermanos lo fabricaban en Capellades) y lo transformaba en papel pintado. 
gracias a los nexos familiares o derivados de la dinámica de distrito ${ }^{56}$. La versatilidad en diversificación ${ }^{57}$, densidad, agilidad, frecuencia de contactos y larga duración de estas redes fueron algunas de las ventajas competitivas del distrito papelero de Capellades. La sede comercial, cuando no era la de Barcelona, se convertía en una prolongación de la empresa sin formar parte de ella. Estos almacenes gozaban de un amplio margen de actuación en las acciones rutinarias, mientras que las de tipo estratégico y táctico se las reservaba la propia empresa.

El uso de esta red para el suministro de materias primas era, en parte, heredero de los rudimentos establecidos en la anterior centuria. Recuérdese que, dadas las características del trapo y las carnazas (mucho volumen y bajo precio), sus tráficos debían insertarse en flujos más amplios ${ }^{58}$. Asimismo, establecimientos comerciales o manufactureros ajenos al sector papelero, creados por naturales de la zona de Capellades, podían ser polos de captación de trapo ${ }^{59}$. La eficiencia de la política de compras era esencial, ya que los papeleros manuales a partir de 1840 competían por el trapo con los fabricantes de papel continuo. Por otro lado, el desarrollo de la industria textil, especialmente la algodonera, proporcionaba crecientes cantidades de trapo. Los fabricantes de Capellades contaban con una posición privilegiada para aprovecharse de ello: insertos en una comarca algodonera y relativamente cerca de Barcelona y Reus. Por tanto, la red de suministro de materias primas tenía sus primeros referentes en la propia región ${ }^{60}$. Esta cuestión refuerza la importancia de las relaciones interindustriales para consolidar las ventajas del distrito papelero de Capellades. Esta red, además, tenía terminales en diferentes puntos de España, especialmente en Andalucía (Málaga, Cádiz y Sevilla), Galicia (La Coruña, punto estra-

56 Antoni Romaní Tort, desde su almacén barcelonés, proveía de trapo y carnazas a diferentes papeleros (familia Serra, Marià Puigdengolas y otros) y comercializaba su papel. Estas conexiones continuaron con su hijo Antoni Romaní Tarrés que tenía vínculos comerciales con sus cuñados (y parientes lejanos) Joan Romaní Massana, Antoni Romaní Miró y Marià Puigdengolas (suegro de los tres). Museo Molí Paperer de Capellades (MMPC, en adelante), Fondo Cal Violant (FCV, en adelante), Correspondencia, 1846.

57 La red se utilizaba para la compra de cereales o productos ultramarinos y para la comercialización de vino. Algunos papeleros también comerciaban con algodón en rama. No en vano, Capellades estaba inserta en una de las principales concentraciones catalanas de hilatura de algodón hasta su declive con la mecanización.

58 Un comisionista catalán establecido en La Coruña comunicaba, en diciembre de 1828, las dificultades de expedir carnazas dado que "como es un género de poco peso y mucho volumen, no hay absolutamente quien quiera fletarse para llevar semejante carga". MMPC, FCV, Correspondencia, 1828.

59 El hijo de un papelero estaba de paso, en noviembre de 1826, en Málaga en casa de Jaume Boloix, corresponsal de diferentes industriales de Capellades, antes instalarse en Adra para montar una panadería. La ciudad almeriense, según Boloix, era "punto [...] bueno para la compra de trapos". MMPC, FCV, Correspondencia, 1826.

60 Antoni Romaní Tort tenía en la década de 1820 en Reus a su primo Francesc Puigdengolas Tort. Allí compraba trapo y borras de desecho del textil algodonero, sector en el que participaba a través de la firma Cusiné y Puigdengolas. 
tégico en el suministro de las carnazas) y Mallorca. Los contactos, más o menos estables, alcanzaron Livorno (uno de los principales referentes del mercado internacional de trapo), Marsella y Cuba.

La proliferación de los almacenes, entendidos como centros de comercialización, debe contextualizarse en la pérdida del dominio directo de los Asientos y de los mercados de las colonias continentales de América (parcialmente recuperados desde 1840). Los primeros pasos de la red se dieron en la segunda década del siglo ${ }^{61}$, su puesta en marcha se acentuó a partir de 1840 y se estabilizó desde 1860. Esta tupida red de almacenes perseguía el contacto directo con el consumidor, reducir riesgos y aumentar garantías en un mercado poco integrado. El "comercial" mantenía informado al fabricante sobre la evolución de la demanda y la presencia de competencia (con especial atención a la alcoyana) ${ }^{62}$. Estas informaciones determinaban, en buena medida, la política productiva de la empresa, tanto respecto a la cantidad como al tipo de papel a elaborar. Esta última decisión era especialmente destacable debido a la existencia de un amplio catálogo con el objetivo de atender a diferentes mercados. Desde Cataluña se remitían a los almacenes principalmente informaciones útiles para fijar la política comercial (como las que incumbían a la producción propia y de la competencia).

La integración de la actividad comercial con la fabricación tenía diferentes grados. Con frecuencia era el propio fabricante quien establecía el depósito en Barcelona, que, de hecho, constituía una extensión de las oficinas de la empresa. Los papeleros del Anoia controlaban claramente el mercado del papel a mano de la capital catalana ${ }^{63}$. El almacén barcelonés, cuando no era regentado por el papelero, se encomendaba a un familiar o a un comisionista de confianza. Los almacenes competían entre sí y con los de los papeleros de otras comarcas, aunque varios fabricantes podían compartir la misma instalación ${ }^{64}$ o podían vender papel de fabricantes que no contaban con depósito propio ${ }^{65}$.

61 Guarro y Puigdengolas se constituyó en 1819 para abrir un comercio en Cádiz. Los socios eran Ildefonso Puigdengolas, natural de Capellades, y Jaume Guarro, de la Pobla de Claramunt. Jaume Serra Franch, propietario de dos molinos en Orpí, contaba con casas comerciales en Barcelona y en Madrid regentadas por hermanos suyos.

62 Ildefonso Puigdengolas afirmaba en agosto de 1826, desde Cádiz, en un mensaje dirigido a Antoni Romaní Tort "Medio Florete no puede ser, porque de Alcoy lo dan muy barato" (MMPC, FCV, Correspondencia, 1826). Puigdengolas informaba en octubre de 1846 que había marginado una remesa de papel de fumar, ya que era demasiado fino "mucho más ahora que entra el invierno que es cuando lo quieren más grueso" (MMPC, FCV, Correspondencia, 1846).

63 Entre los diecinueve fabricantes de papel manual con depósito en Barcelona que participaron en la Exposición de 1860 en homenaje a la reina Isabel II, ocho eran del Anoia. Orellana (1860), pp. 181-185.

64 Este fue el caso de Joan Miquel Llucià y Pau Antoni Miquel, o de Joan Ferrer Pons y Jaume Ferrer Roca, durante la década de 1860.

65 Antoni Romani Tort comercializaba el papel de diferentes fabricantes de Sant Pere de Riudebitlles (MMPC, FCV, Correspondencia, 1827 y 1828). El almacén de Antoni Romaní Tarrés se encargaba de embarcar las cartulinas que Ramon Romaní Miró remitía a Cádiz (MMPC, Caixa Cal Ramonet, carp. 1.851). 
En los depósitos situados fuera de la ciudad condal, el papelero se asociaba con otros $^{66}$ o concedía créditos o facilidades materiales a un pariente o conocido para que lo hiciera ${ }^{67}$. En estos casos, las relaciones con la empresa "madre" se derivaban de contratos de venta en exclusiva que, sin embargo, no vinculaban orgánicamente al almacén con aquélla. Especial interés mereció Andalucía ${ }^{68}$ y, en menor medida, Galicia $^{69}$. Los diferentes vínculos familiares hacían que los proveedores de la zona de Capellades fueran varios y que los contactos pudieran persistir durante muchas décadas ${ }^{70}$. Incluso llegaron a vender papel de otras procedencias y fabricado mecánicamente. Con ello cubrían los segmentos de mercado no satisfechos por sus habituales proveedores. Los almacenes de Barcelona se dedicaban con preferencia a la venta al mayor, aunque en algunos casos también la realizaban al detalle. Más intensa era la actividad minorista en los centros de distribución ubicados en el resto de España.

La red de distribución alcanzó a América, donde fue un resorte fundamental del éxito alcanzado. Las sedes comerciales propias (o con vinculación directa a la empresa productora) y estables ${ }^{71}$ tuvieron su complemento en la existencia de agentes o comisionistas $^{72}$. Puntos de atención preferente fueron Cuba y México. El ejemplo más destacado fue Miquel y Costas Hnos., fundada por Antoni y Llorenç Miquel Costas en 1879 (a partir de 1902, Miquel y Costas E Miquel). Su principal especialidad era el papel de fumar (con la marca "El Pino"). El primer referente de su red comercial

Bartolomé Costas, fabricante de papel de fumar, se asoció en 1845 con Joan Matosa Claramunt para la puesta en marcha de una tienda en Almería.

67 Francesc Ferrer Puigdengolas se asoció en 1842 con Antoni Ferrer Rosich para montar un almacén de papel en La Coruña. Para ello, Francesc Ferrer dispuso del respaldo de su tío y destacado papelero Marià Puigdengolas.

68 Guarro y Puigdengolas se había constituido en 1819 para establecer un comercio en Cádiz y, más tarde, en Sevilla (véase nota 61). Procopi Romaní también se dedicaba en Cádiz, en la década de 1830, al comercio de papel. Bartomeu Costas y Joan Matosa se establecieron en 1845 en Almería. Joaquim y Josep Romaní Massana, hermanos del papelero Joan Romaní, montaron su almacén sevillano en 1842. En 1856 hicieron lo propio José Ferrer Poch y José Vidal Boniquet. Los establecimientos de referencia en Málaga eran el de Jaime Boloix y Cía., el de Joaquim Romaní Puigdengolas, el de Antoni Poch y Josep Creixell, y el de los hermanos Joan y Josep Aguilera.

69 La plaza estratégica en Galicia era La Coruña. El principal establecimiento vinculado con Capellades fue Ferrer y Ferrer, creado en 1842.

70 Ildefonso Puigdengolas, instalado en Andalucía en 1819, aún mantenía fuertes vínculos con la familia Romaní a mediados de la década de 1840. El establecimiento coruñés de Ferrer y Ferrer, que databa de 1842, seguía comerciando con sus parientes y manteniendo con ellos un frecuente trato epistolar y personal en 1888.

71 Este fue el caso de Miguel y Smith y Cía, creada en 1845 para abrir un almacén en La Habana (uno de los socios era el papelero Joan Miquel Llucià), o de Jorba, Borrás y Prats, constituida en 1853 para hacer lo propio en Lima (dos de los socios, Joan Borràs y Joan Prats, eran papeleros de Capellades).

72 En esta red también había naturales de Capellades. Este fue el caso de Romañá Hnos., que negociaba con licores en Cuba y que comercializaba el papel de Pau Miquel Barral. 
fue el almacén establecido por Pau Miquel Costas, hermano de los fundadores, en La Habana $^{73}$. Su vinculación con la empresa continuó a pesar de la muerte de Pau en 1903, fruto del envío en 1906 de Joaquim Muntal, hombre de confianza de los hermanos Miquel. Desde el almacén habanero se distribuyó papel a otros países latinoamericanos, aunque a partir de 1910 se abrieron otras sedes en América (en Valparaíso, México y Buenos Aires). Estos almacenes, al menos formalmente, eran ajenos a la empresa madre ${ }^{74}$, aunque desde Capellades se los controlaba estrechamente.

Estas redes exigían, a su vez, soporte financiero que les diera solidez y credibilidad. Este papel lo cumplieron una serie de banqueros comerciantes originarios de Capellades, aunque establecidos en Barcelona. Los mejores ejemplos durante la primera mitad del siglo XIX son los de Francesc Fontanellas y Joaquim Serra Franch ${ }^{75}$.

\subsection{La gestión del agua}

El impulso que vivió la fabricación manual de papel hasta 1880 incrementó las necesidades de agua, tanto para el suministro de energía (la máquina de vapor se usó en pocos casos) como para su utilización en el propio proceso productivo. En esta etapa la hegemonía de la actividad papelera redujo los conflictos con otros sectores. Las fuerzas de esta red local, especialmente a partir de mediados de siglo, se concentraron en el perfeccionamiento de las infraestructuras hidráulicas y en el aumento de su potencial. Un buen ejemplo procede de la mejora del uso de las aguas de la Font Major de Capellades con iniciativas mancomunadas ${ }^{76}$. Las acciones unitarias se concentraban en la denuncia del mal uso, en el mantenimiento de la red de distribución ${ }^{77}$, en

73 En 1896 se contempló la posibilidad de enviar a Joan, el hermano menor, a México. Arcadi Comas, sobrino de Joaquim Muntal, hombre de confianza en La Habana, se hizo cargo de este mercado en 1910.

74 La sede chilena, según se decía a su gerente, había de contar con una “organización análoga a la establecida con la casa de la Habana [...]. Este negocio de Valparaíso, pues, se ha de desenvolver a nombre de usted, como casa independiente de nuestra razón social". Archivo Miquel y Costas \& Miquel (AMCM, en adelante), Correspondencia, L-bis, f. 268.

75 Fontanellas y Serra, naturales de Capellades, eran suegro y yerno respectivamente. Fontanellas fue el hombre de referencia del Banco de San Fernando en Barcelona, y Serra estuvo entre los promotores del Banco de Barcelona. Fontanellas, desde su juventud, se estableció en Sant Pere de Riudebitlles. Serra, residente en Barcelona desde adolescente, mantenía estrechos contactos con sus hermanos que disponían de molinos en la zona de Capellades.

76 Los papeleros firmaron un acuerdo en 1860 para actuar unitariamente en las cuestiones relativas a la propiedad del agua. AHCI, ANI, Capellades (32), R. Serchs Sala, 1860, f. 309 v.-310.

77 Los fabricantes de papel comunicaron al Ayuntamiento que lamentaban "el deplorable estado de las pequeñas cunetas 'regueras', el cual hace que se desperdicie gran cantidad de agua, y con ello inferir grave prejuicio a sus fábricas". Archivo Municipal de Capellades (AMC, en adelante), Actas del Pleno Municipal, 4, 1874-1880, 12/06/1876. 
su mejora ${ }^{78}$, en el aumento del caudal ${ }^{79}$ y en la institucionalización de su consumo ${ }^{80}$. Entrado el siglo XX, la cooperación se centró en la defensa del acceso al agua, como sucedió en el caso de la conducción de la procedente de Santa Càndia, cerca de Orpí, hacia Igualada ${ }^{81}$. En este marco se formaron agrupaciones como la Unió de propietaris $i$ usuaris de salts d'aigua del Riu Anoia $i$ els seus afluents presidida por el papelero Josep Vilaseca Doménech.

\subsection{Conocimiento y cambio técnico: un ámbito común}

Los papeleros del Anoia tenían una base técnica común con un fuerte contenido tácito y de difícil codificación. Este corpus tecnológico, al mismo tiempo, debía contar con suficiente versatilidad para adaptarse a realidades productivas concretas y cambiantes. El conocimiento socialmente incorporado era esencial para la descentralización de la producción.

El cambio técnico también respondió con frecuencia a dinámicas de cooperación. Las incorporaciones de la pila holandesa (método alternativo a las tradicionales mazas trituradoras del trapo) y del papel vitela (imitación del pergamino) a inicios del siglo XIX lo ejemplifican. Para ello los papeleros de la zona, de acuerdo con los de Sant Pere de Riudebitlles, hicieron venir mano de obra francesa ${ }^{82}$. Estos cambios ya estaban plenamente incorporados al acervo común en las décadas centrales del siglo XIX. Otro ejemplo de la cooperación en el ámbito técnico tuvo lugar con la introducción de la máquina picardo que suponía una tecnología intermedia entre el procedimiento manual y la fabricación continua. El principal objetivo era finalizar con el ciclo huelguístico de la década de 1870. Este ingenio, ideado en Italia, elaboraba mecánicamente las hojas una a una y eliminaba la mano de obra especializada

78 En 1859, después de la desamortización del Molí de la Vila de Capellades, se decía que en las tierras desamortizadas "existe la cañería de agua de las fuentes de esta villa de Capellades, no pudiendo el que posea dicha finca, perturbar su corriente". Se hablaba de "hacer algunas obras para agrandar la balsa y impedir sus filtraciones al objeto de tener más horas seguidas de agua y tal vez en mayor cantidad". MMPC, copia del original, sin clasificar.

79 La práctica totalidad de papeleros de Capellades y la Torre de Claramunt acordaron contratar a un ingeniero de minas para buscar aguas subterráneas. AHCI, ANI, Capellades (27), J. Riera Niubó, 1846-1847, f. 10 .

80 En 1895 se formó una junta interina y se pactó la reforma de la acequia con la participación de los industriales de Capellades. AMC, Libro de actas de reuniones de la Junta Interina de Aguas, 1895-1898.

81 Se afirmaba que "La conducción de estas aguas a Igualada sería la ruina de la Comarca puesto que paralizaría por completo la fabricación de papel y tejidos". El Independiente, 02/10/1910, I, núm. 16, p. 2.

82 Los papeleros de ambos distritos actuaron conjuntamente en 1820 para favorecer la llegada de "los operarios que miren convenientes, aunque sean estos estrangeros, para enseñarnos de fabricar qualesquier especie de papel que no se fabrique en este Principado". AHCI, ANI, Capellades (13), F. Pujol Bordas, f. 100. 
de la tina (el resto del proceso se mantenía prácticamente inalterable). La picardo fue importada, según privilegio de 24 de agosto de 1877, por cuatro empresas radicadas o con origen en el distrito de Capellades: Jover y Serra, Hijos de Romaní y Tarrés, Wenceslao Guarro y Antonio Serra y Sobrino. Previamente, dichas empresas se informaron para conocer las máquinas que cumplían con los requisitos contemplados. Las informaciones llegadas a Cataluña fueron compartidas y la decisión de optar por la máquina italiana también fue colectiva, previos ensayos de un prototipo.

La creciente densificación de la manufactura papelera en las inmediaciones de Capellades permitió aumentar la presencia de servicios técnicos especializados. Ello le otorgaba al distrito una ventaja obvia. Sirva como indicador que sus formaires vendieron sus productos en prácticamente toda España ${ }^{83}$. La carpintería, la herrería y la cerrajería especializadas en la actividad papelera cristalizaron en un activo sector mecánico que servía a fábricas aragonesas y valencianas, entre otras ${ }^{84}$. Para este salto cualitativo fueron decisivas la introducción de la pila holandesa y, especialmente, la adopción de la máquina picardo. Los mencionados servicios y talleres mantenían estrechos vínculos personales y familiares con las principales familias papeleras. En ese marco se establecía un constante flujo de informaciones cruzadas que era fundamental para responder con agilidad y versatilidad a los requerimientos de la demanda.

\subsection{Grupo de presión: aranceles, infraestructuras y acción patronal}

La complicidad y la cooperación derivada de las necesidades productivas de la fabricación de papel tejieron una red de intereses con una clara vertiente política. En este sentido los fabricantes de papel de Capellades tuvieron cierta homogeneidad. Durante la primera mitad del siglo XIX abrazaron el liberalismo. Es destacable esta adscripción en un territorio con fuerte implantación carlista, colocando, de este modo, sus molinos en el punto de mira de los tradicionalistas ${ }^{85}$. Con el avance del siglo su liberalismo fue escorándose a un conservadurismo de base catalanista.

La coincidencia política fue la base para la articulación de un lobby. Sin embargo, los fabricantes de papel de la comarca de Capellades no contaron con ninguna

83 Moldistas como los Ferrer, los Enrich, los Caballé, los Romaña, entre otros, tenían clientes en toda España. Josep Sastach, moldista de Capellades, hizo un viaje en 1826 que le llevó a localidades "papeleras" como Gárgoles de Arriba, Beceite y la Sénia. Madurell (1972), pp. 183-184.

84 Entre los diferentes talleres del distrito de Capellades de la segunda mitad del siglo XIX debe destacarse el de Isidre Soteras, conocido en toda España por la calidad de sus máquinas picardo.

85 En 1839 se decía "que en el término de la villa de Capellades [...] hay unas fábricas de papel blanco que más de cuatro años hace están fortificadas y defendidas por sus operarios". AHCI, Lligalls 1839, 107.2 Varis documents de l'exèrcit. 
agrupación territorial propia, aunque dominaron en las patronales del sector ${ }^{86}$ y en las secciones de las intersectoriales. Su actuación mancomunada tuvo lugar en diferentes campos. El primero fue el arancelario, con posiciones claramente proteccionistas. Se trató de actuaciones unitarias con los de la zona del Riudebitlles o La Riba, como sucedió al inicio del siglo XIX en la lucha contra el contrabando. El lobby de Capellades también estuvo presente durante los cambios arancelarios de $1849^{87}$, de comienzos de la década de $1860^{88}$ y de finales de siglo ${ }^{89}$. Simultáneamente, intentó mantener vedados ciertos mercados al papel continuo, como el destinado a usos oficiales o el de fumar (hasta 1875) ${ }^{90}$.

La mejora de las infraestructuras viarias también fue ámbito de actuación del lobby papelero. El distrito de Capellades había quedado alejado de las principales carreteras por el cambio de trayecto del Camino Real a Madrid a comienzos del siglo XIX. Los papeleros estuvieron presentes en todas las iniciativas para salir de esta situación. El camino a Vilafranca, conexión con el puerto de Vilanova i la Geltrú, fue un objetivo. Lo demuestra que en las comisiones que impulsaron su reforma se encontraran papeleros (Josep Tiana en 1834 y Jaume Ferrer Roca en 1841). Otra actuación prioritaria era la reforma del antiguo Camino Real. Francesc Romaní Puigdengolas, entonces diputado provincial, respaldó, mediada la década de 1860, su mejora. Años después, Marià Puigdengolas fue comisionado para conocer cómo iba el proyecto. Estos intentos cuajaron ya en la década de 1870. Al mismo tiempo, los papeleros fueron agentes activos para sacar a la comarca del aislamiento ferroviario, proceso en el que coincidieron con los algodoneros igualadinos. Las oligarquías económicas, y entre ellas los papeleros, disentían en la plasmación del proyecto. Un

86 Su predominio fue claro en el Gremio de Fabricantes de Papel de Tina a Mano de la Provincia de Barcelona, en la década de 1870, y en la Unión de Fabricantes de Papel de Barba o en la Asociación de Fabricantes de Papel de Hilo o de Barba de España, estas dos últimas constituidas ya entrado el siglo XX.

El Gremio de Fabricantes y Almacenistas de Papel de Barcelona, donde destacaba la presencia de los de Capellades, realizó en 1849 una cuestación para afrontar los gastos derivados de la realización de un documento para ser presentado en el Senado. MMPC, FCV, Correspondencia, 1849.

En 1862, los papeleros de Capellades actuaron conjuntamente con los del resto de la provincia para frenar la prevista reducción de aranceles. Archivo del Congreso de los Diputados (ACD, en adelante), Sección General, leg. 112, exp. $3^{\circ}$, Proposición de ley sobre la introducción de papel extranjero.

89 Ramon Romaní Puigdegolas, reputado papelero de Capellades, ocupó durante esos años la presidencia del Foment del Treball Nacional y de la Liga Nacional de Productores.

90 La prohibición de usar papel continuo en las comunicaciones dirigidas o remitidas por la Administración pública, promulgada el 5 de julio de 1846, aseguró un importante mercado al elaborado manualmente. El motivo aducido fue que el papel mecánico presentaba problemas de conservación. Entrado el siglo XX, esta prohibición seguía vigente. Nicolás Ma de Urgoiti, fundador de La Papelera Española, afirmaba en 1908 que "en España nuestro Ministerio de Hacienda no ha pensado aún en quitar de los pliegos de concurso para la adquisición de papel, la vergonzosa y ridícula condición que obliga á que el papel sea fabricado en tina". Urgoiti (1908), p. 360. 
grupo era partidario de realizar la conexión en Martorell (cuyo representante más conspicuo entre los papeleros era Ramon Romaní Puigdengolas), mientras que otro se decantaba por Sant Sadurní (encabezado por Santiago Serra Crusells). Finalmente triunfó la primera opción, en forma de ferrocarril de vía estrecha que se puso en funcionamiento en 1893.

Una de las piezas de la estrategia productiva de las empresas papeleras manuales, dada la difícil mejora de la productividad, fue disminuir los costes laborales unitarios mediante la prolongación de la jornada laboral o el aumento del tamaño de las hojas de papel. Ambas soluciones afectaban negativamente a las condiciones laborales de los obreros. Los industriales respondieron de forma coordinada a las lógicas protestas sindicales. Durante el ciclo huelguístico de 1867 a 1883, organizados en el Gremio de Fabricantes de Papel de Tina a Mano de la Provincia de Barcelona, afrontaron los paros con despidos y con amenazas a los huelguistas, recurriendo a mano de obra procedente de otras zonas (Beceite y Alcoy, por ejemplo), con el cierre patronal y, finalmente, con la introducción de la máquina picardo. Una coordinación similar volvería a registrarse ya entrado el siglo XX.

\section{Conclusiones}

Una de las particularidades de la industria papelera española fue la larga permanencia de la producción manual. Una zona que ejemplifica esta trayectoria fue la comarca barcelonesa de Capellades. Sus orígenes papeleros se remontan a comienzos del siglo XVII y estuvieron vinculados al suministro de cartones para la manufactura lanera. Cuando llegó el desafío, en forma de creciente demanda a partir de 1760 , su estructura productiva se encontraba ya muy asentada. El resultado fue que, a finales del siglo XVIII, se había articulado como la mayor concentración papelera de España. Este crecimiento fue posible por la existencia de unas rentas externas que, a su vez, retroalimentaba el propio dinamismo. La familia fue la base de la organización de la producción. Su estructura no era en absoluto igualitaria, basándose la jerarquía en la disponibilidad de molinos en propiedad y, muy especialmente, en el control ejercido sobre las contratas públicas. Los papeleros tenían sus ámbitos preferentes de cooperación en el control y administración del agua, en el suministro de la materia prima y en la creación de un lobby en Madrid para conseguir las contratas del Estado. Asimismo, el propio crecimiento facilitó la aparición de una serie de servicios técnicos compartidos. La única alternativa a los núcleos catalanes, muy especialmente al de Capellades, fue la alcoyana, cuyas principales características fueron su súbita aparición y desarrollo durante la segunda mitad del setecientos y su especialización única en el papel de fumar. 
Los núcleos catalanes y valencianos constituyeron el principal ejemplo de la continuidad de la fabricación manual durante buena parte del siglo XIX, mientras iban apareciendo núcleos de fabricación continua en Girona, los alrededores de Madrid y, muy especialmente, en la localidad guipuzcoana de Tolosa. Capellades ejemplifica que la opción tecnológica tomada fue consciente en función de su posición de predominio en unos mercados donde el papel había de ser fabricado a mano. Su hegemonía se basaba en unas estructuras productivas y comerciales que se gestaron en la centuria anterior y que alcanzaron su pleno desarrollo en el Ochocientos. El distrito de Capellades continuó ocupando una posición central entre los productores de papel a mano. Buena parte de sus ventajas competitivas se basaba en la alta concentración productiva. Durante el siglo XIX se agudizó la jerarquización. El grupo dirigente tenía como principales funciones la de coordinar la producción y la comercialización del papel (y la compra de materias primas). Respecto a la primera función debe destacarse que la fabricación se realizaba de forma relativamente descentralizada, incluso utilizando la subcontratación. Este mecanismo otorgaba a los papeleros flexibilidad frente a las fluctuaciones de la demanda y les permitía cubrir diferentes mercados. Respecto a la segunda función, los papeleros construyeron una red con contactos en la práctica totalidad de centros comerciales de España y en América Latina, con la doble función de comprar materia prima y comercializar el papel. Las sedes comerciales solieron ser constituidas por personas originarias del distrito o con parentesco cruzado con miembros de la jerarquía. Sus rudimentos se establecieron durante el siglo XVIII, pero alcanzaron su madurez entre 1840 y 1860 . La existencia de estos almacenes posibilitaba una información rápida y directa de los requerimientos de la demanda. Las redes que articulaban el distrito con los mercados de materias primas y de producto final reforzaron el dominio de las grandes empresas, ya que constituían una barrera de entrada difícil, aunque no imposible, de franquear para los subcontratistas que pensaran superar este estadio.

Durante el siglo XIX se reforzaron las estructuras de control y suministro de agua. También cuajó un corpus tecnológico compartido, esencial para el buen funcionamiento de un sistema descentralizado de producción. Este conocimiento compartido fue ampliándose en el transcurso del siglo, muy frecuentemente con iniciativas mancomunadas. La madurez del grupo oligárquico tuvo su refrendo fuera de los límites estrictos del distrito en el control ejercido sobre las diferentes patronales en que participó.

La organización reseñada fue la base para la subsistencia de la industria papelera en la comarca objeto de estudio. Durante buena parte del siglo XIX y del XX parecía una realidad condenada a periclitar frente al embate de la mecanización. Sin embargo, la concentración productiva y una adecuada elección de nichos productivos, ambas condicionadas por sus raíces históricas, permiten que algunas de sus empresas sean en el presente incluso líderes en sus respectivos segmentos de mercado. 


\section{Fuentes}

Archivo de la Corona de la Aragón (ACA)

Archivo del Congreso de Diputados (ACD, Madrid)

Archivo General de Simancas (AGS)

Archivo Histórico Comarcal de Igualada (AHCI)

Archivo Municipal de Capellades (AMC)

Archivo Miquel y Costas \& Miquel (AMCM)

Archivo Notarial de Igualada (ANI)

Archivo Parroquial de la Pobla de Claramunt (APPC)

Museo Molí Paperer de Capellades (MMPC), Fondo Cal Violant (FCV)

\section{Bibliografía}

ARACIL MARTÍ, Rafael, y GARCÍA BONAFÉ, Màrius (1974): Industrialització al País Valencià: Alcoi, Eliseu Climent, València.

BECATTINI, Giacomo (1986): “Del 'sector industrial' al 'districte industrial'. Algunes consideracions sobre la unitat de recerca de l'economia industrial", Revista Econòmica de Catalunya, 1 (2 època), pp. 4-11.

-(2005): La oruga y la mariposa. Un caso ejemplar de desarrollo en la Italia de los distritos industriales: Prato (1954-1993), Universidad de Valladolid, Valladolid.

-(2006): "Vicisitudes y potencialidades de un concepto: el distrito industrial", Economía Industrial, 359, pp. 21-27.

BENAUL BERENGUER, Josep M. (1996): “Realidades empresariales y estructura productiva en la industria textil lanera catalana, 1815-1870", COMÍN, Francisco, y MARTÍN ACEÑA, Pablo (eds.), La empresa en la historia de España, Madrid, Civitas, pp. 171-200.

BERGER, Suzanne, y PIORE, Michael J. (1980): Dualism and discontinuity in industrial societies, Cambridge, Cambridge University Press.

BETRÁN PÉREZ, Concha (1999): “Difusión y localización industrial en España durante el primer tercio del siglo XX", Revista de Historia Económica, XVII, 3, pp. 663-696.

BRESCHI, Stefano, y MALERBA, Franco (2001): "The Geography of Innovation and Economic Clustering: Some Introductory Notes", Industrial and Corporate Change, 10, pp. 817-833.

BROWN, Jonathan, y ROSE, Mary B. (1993): Entrepreneurship, networks and modern business, Manchester and New York, Manchester University Press.

CASSON, Mark (1997): "Entrepreneurial Networks in International Business", Business and Economic History, 26, pp. 811-823. 
CASSON, Mark, y DELLA GIUSTA, Marina (2004): “The Costly Business of Trust", Development Policy Review, 22, pp. 321-342.

CHANDLER, Alfred D. Jr. (1987): La mano visible. La revolución en la dirección de la empresa norteamericana, Madrid, Ministerio de Trabajo y Seguridad Social (edición original en inglés de 1977).

-(1996): Escala y diversificación. La dinámica del capitalismo industrial, Zaragoza, Prensas Universitarias de Zaragoza (edición original en inglés de 1990).

COROLLEUR, Frédéric, y COURLET, Claude (2003): “The Marshallian Industrial District, an organizational and institutional answer to uncertainty", Entrepreneurship E Regional Development, 15, pp. 299-307.

CRAFTS, Nicholas, y MULATU, Abay (2005): "What explains the location of industry in Britain, 1871-1931?", Journal of Economic Geography, 5, pp. 499-518.

-(2006): "How did the location of industry respond to falling transport costs in Britain before World War I?", The Journal of Economic History, 66 (3), pp. 575-607.

CUEVAS, Joaquim (1999): Los orígenes financieros de la industria de Alcoi (1770-1900), Tesis Doctoral, Alicante, Universidad de Alicante.

DAUMAS, Jean-Claude (2007): “Districts industriels: du concept à l'histoire. Les termes du débat", Revue économique, 58 (1), pp. 131-152.

DEI OTTATI, Gabi (1996): “El distrito industrial y el equilibrio entre cooperación y competencia", Información Comercial Española, 754, pp. 85-95.

ENRIGHT, Michael J. (1995): “Organization and Coordination in Geographically Concentrated Industries", en LAMOREAUX, Naomi, y RAFF, Daniel (eds.), Coordination and Information. Historical Perspectives on the Organization of Enterprise, Chicago, The University Chicago Press, pp. 103-146.

FERROCARRIL DE IGUALADA A SAN SATURNINO DE NOYA (1881): Memoria descriptiva, facultativa y económica, Barcelona, Establecimiento Tipográfico de Luis Tasso.

GIMÉNEZ GUITED, Francisco (1862): Guía fabril e industrial de España publicada con el apoyo y autorización del Gobierno de S. M., Madrid-Barcelona, Imp. L. Tasso.

GUTIÉRREZ I POCH, Miquel (1994): “Tradición y cambio tecnológico: la industria papelera española, 1750-1936", en NADAL, Jordi, y CATALÁN, Jordi (eds.), La cara oculta de la industrialización española, Madrid, Alianza, pp. 341-368.

-(1999): Full a full. La indústria paperera de l'Anoia (1700-1998): continuïtat i modernitat, Barcelona, Publicacions de l'Abadia de Montserrat.

KRUGMAN, Paul (1992): Geografía y comercio, Barcelona, Antoni Bosch.

LABORDE, Alexandre (1809): Itinéraire descriptif de l'Espagne, París.

LA LANDE, Joseph-Jérôme Lefrançais (1778): Arte de hacer el papel, Madrid, Pedro Marín.

LAMOREAUX, Naomi; RAFF, Daniel M. G., y TEMIN, Peter (2003): “Beyond markets and hierarchies: toward a new synthesis of American Business History", American Historical Review, 108, pp. 404-433. 
LANGLOIS, Richard L. (2003): "The vanishing hand: the changing dynamics of industrial capitalism", Industrial and Corporate Change, 12, pp. 351-385.

-(2004): "Chandler in a Larger Frame: Markets, Transaction Costs, and Organizational Form in History", Enterprise \& Society, 5, pp. 355-375.

LARRUGA, Eugenio (1787-1800): Memorias políticas y económicas sobre los frutos, comercio, fábricas y minas de España, Madrid, Imprenta de Benito Cano.

LAZONICK, William (1991): Business Organization and the Myth of the Market Economy, New York, Cambridge University Pres.

-(2004): "The Innovative Firm", en FAGERBERG, Jan; MOWERY, David, y NELSON, Richard (eds.), The Oxford Handbook of Innovation, Oxford, Oxford University Press, pp. 29-55.

LAZZERETTI, Luciana (2006): “Distritos industriales, clusters y otros: un análisis trespassing entre economía industrial y gestión estratégica", Economía Industrial, 356, pp. 59-72.

LECHNER, Christian, y DOWLING, Michael (2003): “Firm networks: external relationship as sources for the growth and competitiveness of entrepreneurial firms", Entrepreneurship \& Regional Development, 15, pp. 1-26.

MADURELL I MARIMON, Josep (1972): El paper a les terres catalanes. Contribució a la seva història, 2 vols., Barcelona, Fundació Salvador Vives Casajuana.

MIRANDA ENCARNACIÓN, José Antonio (1999): “Crecimiento y especialización territorial en la industria española del calzado, 1860-1915", en CARRERAS, Albert; PASCUAL, Pere; REHER, David, y SUDRIÀ, Carles (eds.), Doctor Jordi Nadal. La industrialització i el desenvolupament econòmic d'Espanya, Barcelona, Publicacions de la Universitat de Barcelona, pp. 1.330-1.343.

-(2005): “Calzado y distritos industriales en el Mediterráneo: una visión de largo plazo", Mediterráneo Económico, 7, pp. 289-312.

MUSET I PONS, Assumpta (1997): Catalunya i el mercat espanyol al segle XVIII. Els traginers $i$ els negociants de Calaf $i$ Copons, Barcelona, Ajuntament d'Igualada-Publicacions de l'Abadia de Montserrat.

NADAL, Jordi (1987): “La industria fabril en 1900. Una aproximación”, en NADAL, Jordi; CARRERAS, Albert, y SUDRIÀ, Carles (comps.), La economía española en el siglo XX. Una perspectiva histórica, Barcelona, Ariel, pp. 23-61.

ORELLANA, Francisco J. (1860): Reseña completa descriptiva y crítica de la Exposición Industrial y Artística de Productos del Principado de Cataluña, Barcelona, Establecimiento Tipográfico de Jaime Jepús.

OTTAVIANO, Gianmarco I. P., y PUGA, Diego (1998): “Agglomeration in the Global Economy: A Survey of the New Economic Geography", The World Economy, 21, pp. 707-731.

OTTAVIANO, Gianmarco I. P. y ROBERT-NICOUA, Frédéric (2006): “The 'genome' of NEG models with vertical linkages: a positive and normative synthesis", Journal of Economic Geography, 6, pp. 113-139. 
PAREJO BARRANCO, Antonio (1987): Industria dispersa e industrialización en Andalucía. El textil antequerano (1750-1900), Málaga, Universidad de Málaga-Ayuntamiento de Antequera.

-(1989): La industria lanera española en la segunda mitad del siglo XIX, Málaga, Universidad de Málaga.

-(2006): "De la región a la ciudad. Hacia un nuevo enfoque de la historia industrial española contemporánea", Revista de Historia Industrial, 30, pp. 53-102.

PASCUAL I DOMÈNECH, Pere (1990): “Desenvolupament econòmic i augment de la circulació mercantil. La configuració històrica del sistema d'intercanvis de l'economia anoienca del segle XIX", Miscellanea Aqualatensia, 6, CECI, Igualada, pp. 211-242.

PIORE, Michael J., y SABEL, Charles F. (1990): La segunda ruptura industrial, Madrid, Alianza.

PORTER, Michael (1990): The competitive advantage of Nations, New York, Free Press.

PRAT, Marc (2006): Fabricantes, comerciantes y banqueros. Las estructuras comerciales de la industria algodonera catalana en el mercado español (1840-1936), Tesis Doctoral, Florencia, Instituto Universitario Europeo de Florencia.

PRAT, Marc y SOLER, Raimon (2002): “La formación de las redes comerciales y el fracaso de la penetración internacional de los tejidos españoles, 1850-1930", Revista de Historia Industrial, 21, pp. 201-225.

ROBERT-NICOUA, Frédéric (2005): “The structure of simple "New Economic Geography" models (or, On identical twins)", Journal of Economic Geography, 5, pp. 201-234.

ROOS, Michael W. M. (2005): “How important is geography for agglomeration?", Journal of Economic Geography, 5, pp. 605-620.

ROSE, Mary B. (2000): Firms, Networks and Business Values. The British and American Cotton Industries since 1750, Cambridge, Cambridge University Press.

ROSÉS, Joan Ramon (2003): “Why Isn't Whole of Spain Industrialized? New Economic Geography and Early Industrialization, 1797-1910", Journal of Economic History, 63 (4), pp. 995-1.022.

SABEL, Charles F., y ZEITLIN, Jonathan (1985): “Historical Alternatives to Mass Production: Politics, Markets and Technology in Nineteenth-Century Industrialization", Past and Present, 108, pp. 133-176.

SCRANTON, Philip (1991): "Diversity in Diversity: Flexible Production and American Industrialization, 1880-1930", Business History Review, 65, pp. 27-90.

-(1997): Endless Novelty. Specialty Production and American Industrialization, 18651925, Princeton, Princeton University Press.

TIRADO, Daniel A.; PALUZIE, Elisenda, y PONS, Jordi (2002): “Economic integration and industrial location: the case of Spain before World War I", Journal of Economic Geography, 2, pp. 343-363. 
TOMS, Steven, y WILSON, John F. (2003): "Scale, Scope and Accountability: Towards a New Paradigm of British Business History", Business History, 45, pp. 1-23.

TORRAS I RIBÉ, Josep M. (1974): “Trajectòria d'un procés d'industrialització frustrat. Contribució a l'estudi de la relació entre infraestructura i transformacions industrials", Miscellanea Aqualatensia, 2, CECI, Igualada, pp. 151-197.

—(1993): La comarca de l'Anoia a finals del segle XVIII. Els "qüestionaris" de Francisco de Zamora, Barcelona, Publicacions de l'Abadia de Montserrat.

URGOITI, Nicolás M. (1908): “La Industria Papelera Española”, Boletín de la Industria y Comercio del Papel, II, 45, pp. 359-365.

VALLS I JUNYENT, Francesc (1996): La dinàmica del canvi agrari a la Catalunya interior. L'Anoia, 1720-1860, Barcelona, Ajuntament d'Igualada-Publicacions de l'Abadia de Montserrat.

WILSON, John F., y POPP, Andrew (eds.) (2003a): Industrial clusters and regional business networks in England: 1750-1970, Ahsgate, Aldershot.

-(2003b): "Business networking in the industrial revolution: some comments", Economic History Review, LVI, pp. 355-361. 